\title{
New Technologies for the Sustainable Management and Planning of Rural Land and Environment
}

\author{
Pietro Picuno, Carmela Sica, Alexandra Dimitrijevic, Alfonso Tortora, \\ Rocco Luigi Capobianco, and Dina Statuto
}

\begin{abstract}
New technologies could be adequately introduced for an improved analysis aimed to the sustainable management and planning of the rural land, as well as its environment and landscape. Nowadays, this analysis is easier and more complete through the use of powerful and reliable tools. Several changes can be considered to be as models of territorial development, useful for an appropriate planning of the human interventions in a rural area. Remote sensing techniques could be employed for the monitoring of agricultural land variation, while Geographical Information Systems are excellent tools for landscape modeling and three-dimensional analysis. In this chapter, land-use changes in a rural area located in southern Italy were analyzed by comparing some historical cartographic supports with modern maps, in order to evaluate the morphological and vegetation variations of the agroforestry land during time. Moreover, a landscape analysis was conducted through the implementation of digital terrain models, which were enriched by draping land cover pictures over them. These elaborations finally enabled an evaluation in a scenic way of the aesthetic quality of the agroforestry landscape, allowing a virtual jump back to time periods when digital aerial photography was not yet even possible. This multi-temporal analysis with the support of GIS techniques revealed to have a great potential for assessing and managing landscape diversity and changes of vegetation, as well as for planning sound interventions over the landscape structures.
\end{abstract}

P. Picuno • C. Sica • A. Tortora • D. Statuto $(\bowtie)$

SAFE School of Agriculture, Forestry, Food and Environmental Sciences, University of

Basilicata, Viale dell'Ateneo Lucano 10, 85100 Potenza, Italy

e-mail: dina.statuto@unibas.it

A. Dimitrijevic

Faculty of Agriculture, University of Belgrade, Nemanjina 6, 11080 Beograd - Zemun, Serbia

R.L. Capobianco

Province of Matera, Via Ridola 80, 75100 Matera, Italy

(C) The Author(s) 2015 


\section{Introduction}

Planning and managing the rural land and its environment are one of the most intriguing examples of technical challenge where a multidisciplinary approach plays a crucial role (Picuno et al. 2012). The agricultural production, both food and nonfood, the social role of rural settlements, the state and diffusion of the infrastructural networks, and the rural architectonic heritage that in many countries constitutes a major positive value should be appropriately considered and synergistically interlaced for a sound planning of the agricultural biosystems. Human activities impose a transformation of the extra-urban land that may lead to the modification of the frail equilibrium of whole ecosystems. Sound planning strategies should be therefore pursued, employing a multidisciplinary approach that should take into account geographical, environmental, and landscape factors as variables interacting among themselves and with the social and economic aspects. In order to simultaneously analyze all these properties, tools able to manage, interpret, and integrate several data are necessary.

Extra-urban land planning must pursuit, as a main goal, environmental sustainability, since sustainable development has been perceived all over the world by social awareness and sensibility and is constantly been considered by new laws and regulations whose attempt is the natural resources protection. In this scenario, an accurate analysis of performing variations and a global monitoring of ecosystems are necessary in order to propose environmental protection politics.

The farmer as a producer has traditionally been in focus when changes in agricultural landscapes are studied. Decisions about husbandry, rotational systems, machinery, fertilization, and pest management do indeed affect the landscape in a crucial way, and landscape dynamics cannot be understood if the farmer's decisionmaking and the surrounding technology, socioeconomics, and organizational structure are ignored. However, normally, the farmer is not the only decision-maker. Often, the farms leased land and the owner may be an equally important actor concerning landscape changes. Farmers are important agents in rural landscape management, as they modify landscape elements to suit their needs. The industrialization and intensification of agriculture over the last 50 years had a negative impact on landscape diversity and habitat values. During the last two decades, farmers have become increasingly engaged in landscape activities, to maintain or create habitats on their property. For the sustainable development of rural settlements, at least four characteristics should be protected: balance between nature and built-up area, historic traditional entities, local communities, and the countryside as an own culture. 


\section{New Technologies for Rural Land and Environment Analysis}

New leading technologies could be adequately introduced for an improved analysis of the rural environment. The most currently interesting are:

- Geographical Information Systems

- Remote sensing

- Three-dimensional landscape analysis

\subsection{Geographical Information Systems}

Geographical Information Systems (GIS) are excellent tools for landscape modeling and three-dimensional analysis. They allow an easy digitalization of geographical information and coverage structure, as well as they facilitate graphical representation. An evaluation of the aesthetic impact produced on the rural environment becomes therefore possible, paving the way for landscape simulations and possible minimizations of the landscape impact. GIS allows an easy digitalization of geographical information and coverage structure, as well as facilitating graphical representation (Hernández et al. 2004).

A specific landscape analysis conducted by a GIS approach has shown how positive results of the applied agronomic practices, in terms of $\mathrm{CO}_{2}$ fixation, have been able to contrast heavy emissions of greenhouse effect gases in the atmosphere by urban settlements (Capobianco et al. 2004).

\subsection{Remote Sensing}

Remote sensing techniques could be employed for the monitoring of agricultural land variation. A wide spread of crops covered with plastic can damage the visual landscape, although they are detectable through remote sensing techniques. Some scientific efforts were conducted in order to allow a better monitoring and planning of these uses. Using a field spectrometer, Levin et al. (2007) studied the spectral properties of a sample of polyethylene sheets and various nets used in Israel through the detection of three major absorption features around 1,218, 1,732, and 2,313 nm. Carvajal et al. (2006) presented a methodology able to detect greenhouses from $2.44 \mathrm{~m}$ pixel size QuickBird image, based on an Artificial Neural Network algorithm. Thanks to the information introduced through training sites, they "teach" to the mathematical model to classify the image considering its radiometric and wavelet texture properties. Classification accuracy was evaluated using multisource data, comparing results including and non-including wavelet texture analysis. A 
methodology based on supervised classification of the image was found as the most adequate to the classification of crop shelters. According to this methodology, suitable classes were selected on the basis of signatures related to specific sample areas. The classification was then refined by using neighborhood and contiguity analysis algorithms. The results of the analysis allowed to recognize and localize the crop shelters and to quantify their planimetric area. The latter was also compared with the attributes of georeferenced feature classes based on visual recognition. Finally, Capobianco and Picuno (2008) implemented remote sensing techniques aimed to the analysis of the rural land use, with special attention paid to greenhouse and other application of plastics in protected cultivation, inside a study area located near the coast border between the Italian regions of Basilicata and Apulia, where plastic in agriculture is widely used. The analysis was realized using Thematic Mapper of multi-temporal Landsat images through supervised classification, image processing, vectorization, and GIS tools. For the study, band 7 $(2.08-2.35 \mu \mathrm{m})$, band $5(1.55-1.75 \mu \mathrm{m})$, and band $3(0.63-0.69 \mu \mathrm{m})$ were used, together with other suitable cartographic information. The results that were obtained enable the possibility to create a routine in IDL and ENVI software for the autodetection of the plastic covers.

\subsection{Three-Dimensional Landscape Analysis}

Through the implementation of a digital terrain model (DTM), enriched with the drape of land cover pictures, Capobianco et al. (2004) evaluated in a scenic way the morphological and vegetation variations of agroforestry landscape.

Solid modeling techniques, moreover, could contribute to the analysis and planning of the rural environment. The implementation of a digital terrain model (DTM), enriched with the drape of land cover pictures, enables the evaluation in a scenic way of the morphological and vegetation variations of agroforestry landscape. From the digitalization of historical cartography, enabling the analysis of the natural and anthropic changes of rural land using a Geographical Information System and image processing techniques, Tortora et al. (2006) analyzed the aesthetic impact that the use of plastic coverings produces on the rural environment, so enabling landscape simulation and examining possible minimizations of the landscape impact.

The digitalization of historical cartography, finally, allowed (Picuno et al. 2011) the simulation of a hypothetical and virtual historical jump backward, so facilitating the analysis of the natural and anthropic changes of rural land during time. 


\section{Application of New Technologies on Historical Maps for the Analysis of the Agroforestry Land Evolution}

Sound planning strategies should be pursued, employing a multidisciplinary approach that takes into account geographical, environmental, and landscape factors as variables interacting among themselves and with social and economic aspects (Tortora et al. 2006). Over recent years, different systems have been developed with the aim of providing support to policy makers in the field of agricultural development (Van Delden et al. 2010). According to this scenario, an accurate analysis of the performed variations and the global monitoring of all ecosystems are necessary to propose suitable environmental protection politics (Picuno et al. 2011). The visualization of spatial information in the form of maps is critical to facilitating decision-making in environmental management (IosifescuEnescu et al. 2010).

Moreover, the technical and spatial analysis methodologies that have been recently developed could ensure both the proper management and planning of land, especially if tailored to environmental protection and to efficient control of the agricultural and forestry resources. Suitable models for policy impact assessment (Brown and Brabyn 2012) should help to harmonize the EU agricultural policies and socioeconomic processes at different levels and in different sectors (i.e., local zoning regulations, infrastructure planning, and interaction between these sectors) as well as external factors such as climate change and socioeconomic drivers (Van Delden et al. 2010). Landscapes are spatially diverse, leading to the unequal distribution of landscape services over an area. An evaluation of the policy effects should therefore be spatially explicit as policies are likely to have a locationspecific effect on the provision of landscape services (Willemen et al. 2010). An ex-ante evaluation of the consequences of spatial planning and policy on the supply of landscape services can support effective decision-making (Verburg et al. 2009).

The analysis of the historical landscape and the influential driving factors of landscape development may provide an essential basis for tackling current environmental questions in spatial planning (Haase et al. 2007). The landscape should be understood as a dynamic and open system where biophysical, social, and economic factors interact to define the current structure. The knowledge of historical landscape development ought therefore to be a starting point for long-term landscape monitoring. In most landscapes, large-scale patterns of geological, topographical, and morphological alteration are overlaid by smaller-scale variations in microclimate and disturbance patterns. Landscape processes are nested in a spatiotemporal hierarchy, from large-scale, slow processes like geological change to smaller-scale, rapid processes like plant competition and succession (Gillson 2009).

In order to evaluate the processes involved, suitable information about the landscape, the land-use structure, and the environment are required. The spatiotemporal dynamics of traditional rural mountain landscapes reflect the land-use evolution over the centuries resulting from the long-standing interaction between people and the environment and recent changes due to the impact of population 
migrations and policies influencing land use (Cullotta and Barbera 2011). That interaction between man and environment led to the development of traditional landscapes whose characteristics are closely linked to many features of the local geography, climate, water availability, soils, and the historical occupation of a region (Pôças et al. 2011). A time series can be used to predict future general trends in the case of assumed constant political and economic frameworks. The generated scenarios can be considered a projection of future land-use changes or a description of the relationships between the driving forces of environmental changes and their evolution. In order to generate these future scenarios, the dynamics of land-use patterns can be "simulated" taking into account the initial state of the system, the participating factors in land-use dynamics, and the rules that produce the dynamics that drive the evolution of actual cities.

Regional and local investigations of landscape change (Schneeberger et al. 2007) enable land-use trends and developments to be differentiated by region and hence support analysis of the causes of the changes (Haase et al. 2007). A multitemporal analysis of land, with the support of GIS and historical documents, is very important for monitoring landscape diversity (Yeh and Huang 2009) and for investigating changes in vegetation and landscape structure (Leyk et al. 2006).

Vegetation plays an important role in human life and economic activity. The economic role of vegetation is dependent on its ecological function, which is of particular importance like determines the top priority of taking them into account in the system of rational nature management. In addition to vegetation, there are other elements that have a correlation with the landscape, such as buildings, which should be appropriately considered in data processing (Picuno 2012). There is often a difficult relationship between rural buildings and the landscape (Jeong et al. 2012). European landscape planning policy has particular building codes that protect local cultural identity and promote landscape quality (Council of the European Union 2001).

To understand the territorial and landscape changes that have occurred over the years, especially in Europe, it is important to recognize the limits of expert approaches and to integrate them with the use of various tools (participatory GIS, semi-directed meetings, photo-elicitation, cognitive mapping, etc.), which allow individual evaluations to be established (Domon 2011).

Geographical Information Systems (GIS) are excellent tools for landscape modeling, for knowing about changes of vegetation, and for conducting threedimensional analyses. They allow an easy digitalization of geographical information and coverage structure, and they facilitate graphical representation (Hernández et al. 2004). The morphological and vegetation variations of agroforestry in the landscape may be evaluated through the implementation of a digital terrain model (DTM), over which the land cover picture is draped; further elements can be successively introduced in a rural landscape and may be included with the aim of understanding the changes occurring in the landscape. Spatial data combined with GIS-based modeling and interpretation using detailed Digital Elevation Models (DEMs) and orthophotos are very useful tools as well. Spatial information is, as a rule, visualized using photographic and thematic maps (Gehrke et al. 2006). While 
photographic maps claim to be an accurate reproduction of the original settings, thematic maps portray their content in an abstract form, while the topology of spatial units is maintained (Olbrich et al. 2002). Here, GIS was used to integrate and manage different kinds of data and to create high-quality maps that incorporated many other layers of information. Also, orthophotos, maps, and models were integrated in a $3 \mathrm{D}$ viewer to improve interpretations. Partial results from each approach were coordinated and iterated to obtain the best fitting result (Elez et al. 2013). Strengthened by the knowledge of the importance of time as a dimension, and relying on the advances in the field of cartography and spatial analysis, several studies have examined the dynamics generated by the transformation of agricultural or forest exploitation contexts, as much for landscape (spatial composition and organization) as for ecological (in support of biodiversity) reasons.

However, specifically during the last two decades, three strong tendencies have led to the relative importance of these resources to local rural economies being questioned. Firstly, the increased mechanization and concentration of exploitation have resulted in a general decrease in the importance of the primary sector (agriculture and forestry) within rural communities, with their socioprofessional structure increasingly resembling that of more urban environments. The new technologies cited are therefore here used to analyze land-use dynamics and topographic changes over almost two centuries (from 1848 to 2012).

\subsection{Study Area}

The study area (about $25 \mathrm{~km}^{2}$ ) is a part of the Ruoti Municipality (Fig. 1), located in the central-western part of the Basilicata region of southern Italy $\left(40^{\circ} 43^{\prime} 05.43^{\prime \prime} \mathrm{N}\right.$, $\left.15^{\circ} 40^{\prime} 32.12^{\prime \prime} \mathrm{E}\right)$. The Basilicata region embodies much of the variability of landscapes found in southern Italy. In addition to the geological variability, the territory of the region has a remarkable morphological variability, with the presence of surfaces dating to very different ages and a great variability of soils that were
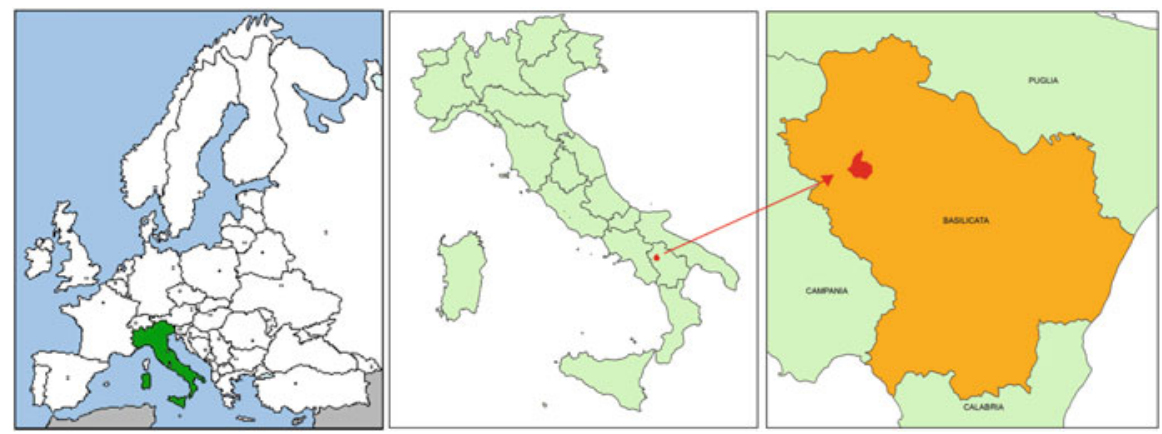

Fig. 1 Study area located in Basilicata region (southern Italy) 
formed within these environments. This area is characterized by a hilly/mountainous terrain, and elevations are within the range of $400-1,000 \mathrm{~m}$. The rainfall during the year is on average $751 \mathrm{~mm}$. This area includes two fundamental complexes, one limestone and dolomite (carbonate series) and the other is largely terrigenous and defined by flysch. The geomorphological features of this area are related to the character of the outcrops. The study area is crossed by the Fiumara di Avigliano and is bounded in the south by the Fiumara di Ruoti. Both rivers are part on the hydrographic basin of the river Sele. The study area is predominantly occupied by agricultural land (57\%), forested and seminatural land area (38\%), and artificial surfaces $(5 \%)$. The high hilly landscape of the study area is characterized by arable land, which is present especially in the hills, with wide pastures and vineyards in the northern area. The mountains are covered with rich woodlands, consisting mainly of underwood, such as fir-wood, with elements of Abies alba (a biotope surveyed by the Italian Botanical Society).

The Municipality of Ruoti is characterized by an economy that is mainly based on agriculture, but some industrial activities are present. Cereal crops are widespread, as well as herds of sheep and goats, whose milk gives an excellent cheese. Wheat, fodder, and vegetables are grown, and there are olive groves, orchards, and vineyards, the latter producing the well-known Asprinio wine. The industry is mostly aimed to the food sector, the main product being milk.

Ruoti is a center of ancient origin, dating back to pre-Roman times, as demonstrated by a series of finds. The territory has been subjected over the centuries to domination by different groups, as evidenced by historical and architectural finds such as churches and monuments.

\subsection{Cartography}

To understand the changes that have affected the study area during the last two centuries, four different time steps (years) were analyzed: 1848, 1877, 1953, and 2012. The maps were firstly scanned and digitized within a Geographical Information System, then the land-use categories and elevations from each map were extracted, and the differences among the different time levels were evaluated (Tucci and Giordano 2011). Through the digital processing of the maps that were found, it was possible to reconstruct the three-dimensional shape of the land in the study area and, thanks to a photomosaic procedure, achieve a virtual reconstruction of the land during these different time periods. However, before using the information contained in old maps for historical studies, its quality had to be assessed and some aspects need to be considered: the topographic accuracy that denotes the quantity and quality of information about landscape objects; the chronometric accuracy, in other words, the dating of the map and the dating of the information contained in the map; and the planimetric completeness (or geometric accuracy) (Jenny and Hurni 2011). 


\subsubsection{The 1848 Historical Map}

The first historical maps were produced after border disputes by legal experts; an historical map of the Municipality of Ruoti was produced in 1848 to resolve border disputes and it remained the main document of the historical memory, representing the whole territory for investigations of the land. This map shows the land that was studied and measured during the division of the former feudal domains and the subsequent controversy. It constitutes a complete cartographic support with thematic information about the land use at that time. The map reports on the town and the surrounding area and shows the main rivers in the area (Fiumara di Ruoti and Fiumara di Avigliano); in the north of the area, there are lands present that can be classified as nonirrigated arable land and irrigated land; in the central part of the territory, there is an alternation of olive groves and arable crops; while in the eastern part, a set of symbols describes the layout of the vineyards. It also appears that a portion of land is classified as woodland. The legend located with the western part of the map shows the territorial extension of the categories of vegetation that are here represented. The place names of various districts are reported too; however, the farms and the roads within the area are unfortunately not reported at all.

\subsubsection{The 1877 Map}

The morphology and land use for 1877 were analyzed through a topographic map of the Italian Topographic Military Institute (ITMI), named after 1882 as Italian Geographic Military Institute (IGMI). The scale of the map was 1:50,000; it has been digitized through a process of scanning and georeferencing. The map shows in black and white contour lines with an equidistance of $10 \mathrm{~m}$ and gives some information about the toponyms and the presence of farms. The projection is an amended Flamsteed, and the coordinate's origin is at the intersection of the meridian of Naples with the 40th parallel. The study area falls into two sheets (sheet no. 65 "Avigliano," both its western and eastern part).

\subsubsection{The 1953 Map}

The stereoscopic aerial coverage of the national territory was made through photogrammetry (each photogram was shot with a camera equipped with a lens with focal length of $152 \mathrm{~mm}$, the size of the photo is $230 \times 230 \mathrm{~mm}$, and its approximate scale is $1: 33,000$ ). The analysis of the land use relative to 1953 was possible by an aerial photogrammetric survey that was performed in the 1950s, from which the different categories of land use of the study area were obtained. From the morphological point of view, a map of IGMI (scale 1:25,000) was used as the basis for entering the contour lines. So, it was possible to derive the elevations of the area and subsequently, through appropriate GIS elaborations, the Digital Elevation Model. 


\subsubsection{The 2012 Map}

To determine the land use for 2012, digital orthophotos were utilized. Digital orthophotos combine the image characteristics of a photograph with the geometric qualities of a map. Unlike a standard aerial photograph, relief displacement in orthophotos has been removed so that ground features are displayed in their true ground position. This allows for the direct measurement of distance, areas, angles, and positions. The orthophotos are able to display actual ground features; in the ideal situation, one aerial photograph will be used to create an entire orthophoto which allows the identification of a great level of detail. The photography is scanned and converted into a digital image from which it is subsequently possible to identify a great number of elements: land use, farms, vineyards, olive groves, and basins for water collection. The morphology of the land was derived from the Digital Elevation Model (DEM, with a cell size of $20 \mathrm{~m}$ ). In addition, using specific tools - namely, slope (the inclination of a surface) and aspect (that can be generated from continuous elevation surfaces, usually measured in degrees from north) - the main features of the studied area were evaluated.

\subsection{Data Analysis}

For each considered time period, and taking into account the different base maps that were presented above, various categories of land use were identified, considering the symbols available on the map and the level of detail of the cartographic base. In the case of the historical map, the different categories of land use were well marked and six categories have been identified. Through the Italian Topographic Military Institute (ITMI) map, the analysis even of the suburban nucleus in the area has been identified, in addition to various forms of vegetation. Eight different categories of land use have been therefore identified. The land use for 1953 was derived from the analysis of georeferenced aerial photos, which showed a greater degree of detail, where it is possible to identify 10 categories; finally, in the color orthophotos for the 2012 map, no. 11 different categories of land use have been identified. In order to make the data more uniform and allow a more direct comparison, the main categories of land use have been therefore aggregated and defined as "elements."

In the study area, four major "elements" were identified. For each of them, using the GIS function, the total area expressed in hectares (ha) and the percentage of the study area were calculated. Their variation over the years was also calculated. The most important elements found in this area are rivers, urbanized areas, natural land, and agricultural land described as follows:

Rivers These were considered in their areal extent, that is, the bed of the river and the vegetation present along the river, both as their linear extension. Streams and rivers cause erosion, sediment transport, and changes in the flood plain and floods. 
Most of the erosion process is accomplished both by rainwater and by surface waters that flow downstream. Streams and rivers, through their action, are able to change the morphological structure through their erosive action by creating channels, canyons, and valleys and by transporting deposits of solid material to flood plains and deltas. Much of the current landscape is the result of an erosion process.

Urbanized Area This includes the town, the old buildings and those from recent expansion, and the buildings and farms present in rural areas. Most of the current urbanized land is covered by structures.

Natural Land This includes forest and transitional woodland and shrubland. Forests are mainly composed of vegetation, principally trees, but also include shrub and bush understory, where broad-leaved species are prevalent. Transitional woodland can represent either woodland degradation or forest regeneration/ recolonization. Natural land is formed by bushy or herbaceous vegetation with scattered trees.

Agricultural Land This comprises arable land, olive groves, vineyards, pastures, and natural grassland. Arable land includes cereals, legumes, fodder crops, root crops, and fallow land. It includes trees crops and vegetables, whether in open fields or in greenhouses. The olive groves consist of areas planted with olive trees, where the simultaneous presence of olive trees and vineyards can be detected as well. Natural pastures are areas with spontaneous herbaceous vegetation.

\subsection{Results}

From the superimposition of the different base maps, it was possible to identify the different categories of land use. The number of classes identified increased at each step in time, mainly due to the improved detail provided by the evolving cartographic information. The results of this territorial analysis are presented in Table 1 and Fig. 2. To make the analysis and the comparison of the categories of land use over the years more uniform, they were suddenly aggregated into only four main "elements": agricultural land, natural area, fluvial zone, and urbanized area.

The analysis of the data related to land use in different periods shows the variation in terms of the percentage with respect to the entire area; the forested

Table 1 Analysis of elements over the years

\begin{tabular}{|c|c|c|c|c|}
\hline \multirow[b]{2}{*}{ Year } & \multicolumn{4}{|l|}{ Elements } \\
\hline & Fluvial zone (\%) & Urbanized area $(\%)$ & Natural area $(\%)$ & Agricultural land (\%) \\
\hline 1848 & 4 & 1 & 10 & 85 \\
\hline 1877 & 6 & 1 & 18 & 75 \\
\hline 1953 & 7 & 2 & 22 & 69 \\
\hline 2012 & 5 & 7 & 44 & 44 \\
\hline
\end{tabular}



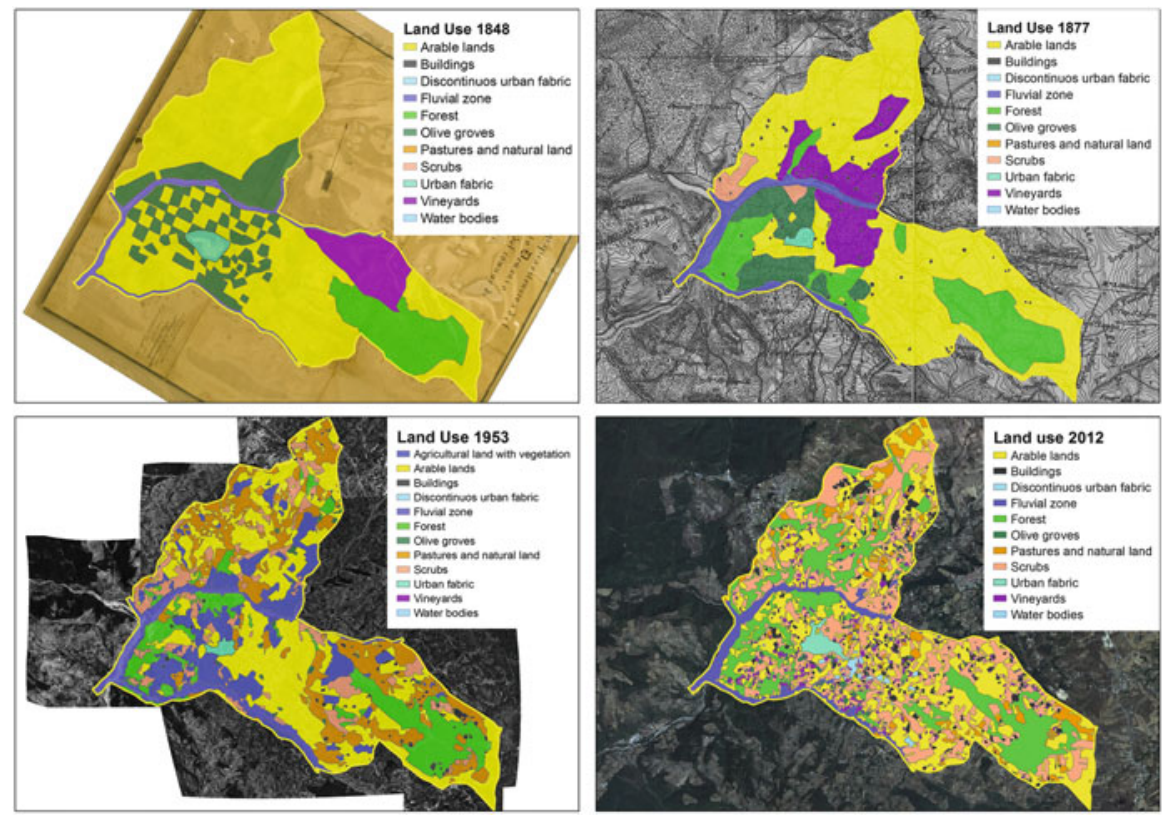

Fig. 2 Land-use categories in different periods

area has increased from about $10 \%$ in 1848 to $18 \%$ in 2012, the river area increased to $7 \%$ in 1953 and then fell to $5 \%$ in 2012, and the percentage of land used for arable land has decreased significantly from $61 \%$ in 1848 to $33 \%$ in 2012, while the urban fabric has increased over the years, especially after the Second World War. The main difference that occurred, as a part of a widespread trend also detected in other areas of the Basilicata region due to deep social and economical modifications occurred on time, was therefore a mutual exchange between the areas of agriculture and crops, which reduced by almost a half, giving more space to the natural areas.

From the analysis of the contour lines derived from maps from the years 1877, 1953, and 2012, it is possible to obtain the digital terrain models (DTM), thanks to an appropriate processing. These data, adequately treated with spatial analysis procedures, allowed an evaluation of the morphological changes in terms of elevation of the study area. All the four elevation profiles have changed over the years. The altimetry has changed, mainly when the lines for the periods 1877 to 1953 are compared, showing a general reduction of the altimetry of the examined area. This event should be probably connected with the general evolution over time of the morphology of the land, mainly connected with natural events like floods, landslides, and soil erosion, so frequent within this area, causing most of the morphological changes that have occurred over the years.

The contour lines obtained from the digitization of the map for 1877 have allowed the development of digital terrain models. Using spatial analysis functions, 


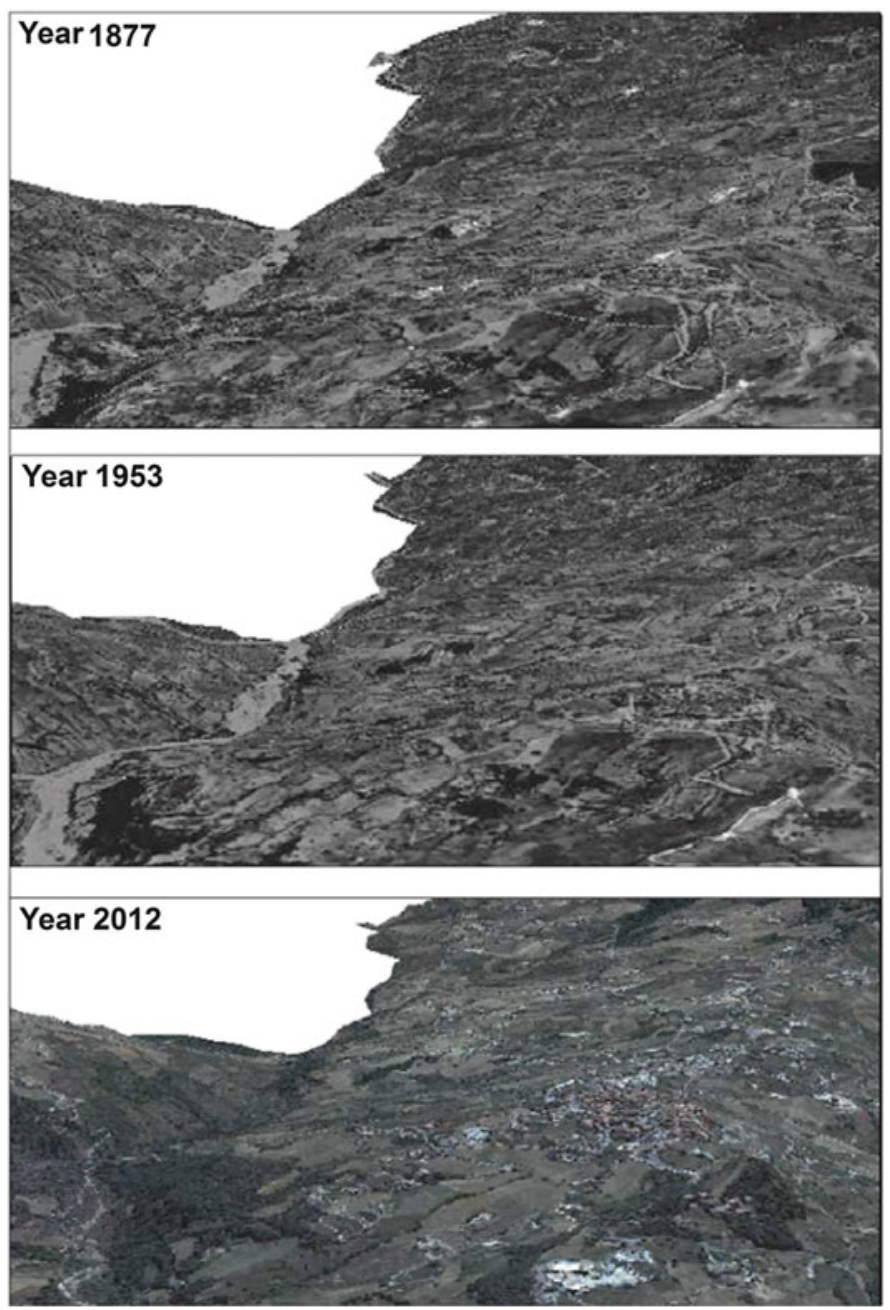

Fig. 3 Comparison of three-dimensional landscape

the map of year 1877 was appropriately correlated to the altimetry (DEM) of that year. Proper spatial analysis procedures have enabled the realization of threedimensional views in order to appreciate the landscape changes. Figure 3 shows an image obtained from the solid modeling of the 1877 map on which a "virtual orthophoto" of the same year was draped. The virtual orthophoto reported here was associated with the visualization of the land use in 1877 on the aerial photo, so obtaining the reconstruction of the landscape for 1877 . The picture was compared with the same images for 1953 and 2012. From the comparison between the threedimensional reconstructions, it is possible to appreciate the landscape changes qualitatively and the aesthetic quality of the study area in terms of the morphological and vegetative variations of the agroforestry landscape. 


\section{Analysis of Time Evolution of Agroforestry Land as a Tool for the Sustainable Management and Planning of Rural Land andEnvironment}

From the analysis of land-use evolution that was here performed, it can be noticed how, during the investigated time spans of about 160 years, the land used for agricultural production has progressively decreased, to the benefit of the natural areas that have in the meantime expanded, occupying most of the area lost by the former. This phenomenon was probably due to the constant increase of agricultural mechanization and diffusion of chemical products into intensive agriculture, which led many traditional farmers to abandon their estates and to consequently transfer into the urban area. Thus, this phenomenon has allowed a natural vegetation to grow over the years, spontaneously covering areas that were cultivated in the past. The increase in urbanization is the result of the development of this territory, but its expansion without a proper development policy has facilitated the proliferation of residential areas with the consequent abandonment and fragmentation of the rural territory and its landscape.

An appropriate environmental approach could also be revealed to be useful if focused on the balance of carbon dioxide fixation connected to different crop strategies. All the land changes detected in the study area have caused a progressive decrease in carbon dioxide sequestered by the biotic agents embedded in the soil. The cultivation conversion occurred over time and the increase of urban areas caused a consequent constant loss of the $\mathrm{CO}_{2}$ fixation value, while the heavy emission of greenhouse effect gas in the atmosphere by urban settlements has been increasing at the same time (Statuto et al. 2013).

Considering the elevation profiles obtained, it is possible to observe that the altimetry data relating to 1877 was consistently higher than for later periods. The profiles obtained from the elevations of 1953 and 2012 are very similar to each other, so it is possible to attribute the differences to the presence of small rivers that, over the years, have had a deepening of their beds. This situation is typical of the whole area of the Apennines, since it is connected to a strong hydrogeological instability.

The landscape analysis using the three-dimensional modeling allowed the evaluation of the simultaneous changes both in land use and in the morphological variations that involve landscape modification. Figure 3 shows that a great part of the territory has significantly changed: some of the areas that in 1877 were covered by forests have, over the years, turned into arable land, so determining a clear change in the visual quality of the rural landscape.

The analysis that was performed over the three-dimensional images of the territory has been revealed to be a powerful means of interpretation, since it allows some dynamic effects to be created in a virtual reality system, in which the operator has the opportunity to navigate as walking or flying over the area at that time; thus, the operator is able to visit—with a virtual jump back in time enabled by the simulation of an ante litteram flight - real-life scenarios that would be otherwise 
difficult to imagine and/or reach. Then, all the aspects characterizing that area can be examined in suitable detail and completeness, starting from the analysis of topography and land cover and leading to anthropic components (buildings, roads, and railways, hydraulic infrastructure such as dams, aqueducts, etc.).

\section{Conclusions}

The role of territorial analysis is extremely important and delicate, especially if carried out to pave the way for proper planning activities. The understanding of the landscape's evolution over the years, both in morphological and vegetation terms, represents a highly valuable database usable by public decision-makers in the normal processes of making economic and political choices for the government of the territory. All of this should be in harmony with the historical changes in the rural territory that current events, according to the modern ways of conceiving the suburban areas, bring into play over social aspects closely related to the traditions and customs of the past.

The evolution of computer technology, coupled with the availability of historical maps, has proved to be a decisive tool in the creation of appropriate instruments for the representation of agricultural land and forest, which could allow an effective step forward to be taken in the process of encouraging sustainable economic development. This phenomenon caused a corresponding increase in the natural vegetation area, but also an increase in surface erosion due to an improper land management.

The analysis of the evolution of land use over a long time period — as in this case, where nearly two centuries were considered - can show how the results of the applied agronomic practices, in terms of $\mathrm{CO}_{2}$ fixation, would be able to compensate for heavy emissions of greenhouse effect gases in the atmosphere by urban settlements. This would demonstrate how correct rural site management could efficiently balance environmental pollution brought about by human development. The spatial analysis that was conducted allowed to understand the landscape dynamics of the past, current developments, as well as possible future trends. Similar information should be adequately considered to help in addressing the need for suitable development policies and appropriate land management planning.

Open Access This chapter is distributed under the terms of the Creative Commons Attribution Noncommercial License, which permits any noncommercial use, distribution, and reproduction in any medium, provided the original author(s) and source are credited. 


\section{References}

Brown G, Brabyn L (2012) An analysis of the relationships between multiple values and physical landscapes at a regional scale using public participation GIS and landscape character. Landsc Urban Plan 107:317-331

Capobianco RL, Picuno P (2008) Remote sensing and thematic mapping of protected cultivation in Southern Italy agricultural landscapes. In: Abstracts of the AgEng2008 conference: agricultural engineering and industry exhibition, Crete (Greece), 23-25 June

Capobianco RL, Tortora A, Picuno P (2004) Analisi del territorio, dell'ambiente e del paesaggio rurale mediante tecniche di modellizzazione spaziale ed image processing di cartografie storiche [Analysis of rural land, environment and land scape through spatial modelling techniques and historical cartography image processing]. Riv Ing Agr 35(3):71-77 (in Italian)

Carvajal F, Crisanto E, Aguilar FJ, Aguera F, Aguilar MA (2006) Greenhouses detection using an artificial neural network with a very high resolution satellite image. In ISPRS technical commission: II symposium

Council of the European Union (2001) Council resolution on architectural quality in urban and rural environments (2001/C 73/04). Off J Eur Commun, C73, 6/3/2001

Cullotta S, Barbera G (2011) Mapping traditional cultural landscapes in the Mediterranean area using a combined multidisciplinary approach: method and application to Mount Etna (Sicily; Italy). Landsc Urban Plan 100:98-108

Domon G (2011) Landscape as resource: consequences, challenges and opportunities for rural development. Landsc Urban Plan 100:338-340

Elez J, Cuezva S, Fernandez-Cortes A, Garcia-Anton E, Benavente D, Cañaveras JC, SanchezMoral S (2013) GIS-based methodology to quantitatively define an adjacent protected area in a shallow karst cavity: the case of Altamira cave. J Environ Manage 118:122-134

Gehrke S, Wahlisch M, Lehmann H, Albertz J, Neukum G, HRSC-Team (2006). Planetary mapping with "Pimap". In: 5th international symposium Turkish-German joint geodetic days

Gillson L (2009) Landscapes in time and space. Landsc Ecol 24:149-155

Haase D, Walz U, Neubert M, Rosenberg M (2007) Change to Central European landscapes: analysing historical maps to approach current environmental issues, examples from Saxony, Central Germany. Land Use Policy 24:248-263

Hernández J, García L, Ayuga F (2004) Integration methodologies for visual impact assessment of rural buildings by geographic information systems. Biosyst Eng 88(2):255-263

Iosifescu-Enescu I, Hugentobler M, Hurni L (2010) Web cartography with open standards: a solution to cartographic challenges of environmental management. Environ Model Softw 25:988-999

Jenny B, Hurni L (2011) Studying cartographic heritage: analysis and visualization of geometric distortions. Comput Graph 35:402-411

Jeong JS, Garcìa-Moruno L, Hernàndez-Blanco J (2012) Integrating buildings into a rural landscape using a multi-criteria spatial decision analysis in GIS-enabled web environment. Biosyst Eng 112:82-92

Levin N, Lugassi R, Ramon U, Braun O, Ben-Dor E (2007) Remote sensing as a tool for monitoring plasticulture in agricultural landscapes. Int J Remote Sens 28:183-202

Leyk S, Boesch R, Weibel R (2006) Saliency and semantic processing: extracting forest cover from historical topographic maps. Pattern Recognit 39:953-968

Olbrich G, Quick M, Schweikart J (2002) Desktop mapping: Grundlangen und Praxis in Kartographie und GIS-Anwendungen, 3rd edn. Springer, Berlin, p 30

Picuno P (2012) Vernacular farm buildings in landscape planning: a typological analysis in a southern Italian region. J Agric Eng XLIII(e20):130-137

Picuno P, Tortora A, Capobianco RL (2011) Analysis of plasticulture landscapes in Southern Italy through remote sensing and solid modelling techniques. Landsc Urban Plan 100:45-56 
Picuno P, Tortora A, Sica C, Capobianco RL (2012) New technologies for ecosystem analysis planning and management, diversity of ecosystems, InTech, pp 299-338

Pôças I, Cunha M, Pereira LS (2011) Remote sensing based indicators of changes in a mountain rural landscape of Northeast Portugal. Appl Geogr 31:871-880

Schneeberger N, Bürgi M, Kienast PDF (2007) Rates of landscape change at the northern fringe of the Swiss Alps: historical and recent tendencies. Landsc Urban Plan 80:127-136

Statuto D, Tortora A, Picuno P (2013) Analysis of the evolution of landscape and land use in a GIS approach. In: Proceedings of the first international symposium on agricultural engineering ISAE 2013, session VI, October, 4-6, 2013. Belgrade, Serbia, pp 25-33

Tortora A, Capobianco RL, Picuno P (2006) Historical cartography and GIS for the analysis of carbon balance in rural environment: a study case in Southern Italy. Agric Eng Int CIGR EJ VIII

Tucci M, Giordano A (2011) Positional accuracy, positional uncertainty, and feature change detection in historical maps: Results of an experiment. Comput Environ Urban Syst 35:452-463

Van Delden H, Stuczynski T, Ciaian P, Paracchinie ML, Hurkensa J, Lopatka A, Shi Y, Prieto OG, Calvo S, van Vliet J, Vanhout R (2010) Integrated assessment of agricultural policies with dynamic land use change modelling. Ecol Model 221:2153-2166

Verburg PH, van de Steeg J, Veldkamp A, Willemen L (2009) From land cover change to land function dynamics: a major challenge to improve land characterization. J Environ Manage 90:1327-1335

Willemen L, Hein L, Verburg PH (2010) Evaluating the impact of regional development policies on future landscape services. Ecol Econ 69:2244-2254

Yeh CT, Huang SL (2009) Investigating spatiotemporal patterns of landscape diversity in response to urbanization. Landsc Urban Plan 93:151-162 